\title{
Model Updating of Friction Stir Welding for Aluminium and Magnesium Plate Structure
}

\author{
Nazrotul Afina Nazri ${ }^{1}$, Mohd Shahrir Mohd Sani ${ }^{1,2^{*}}$, Muhammad Nasiruddin Mansor ${ }^{2}$ and Siti Norazila Zahari ${ }^{1}$ \\ ${ }^{1}$ Advance Structural Integrity and Vibration Research (ASIVR), Faculty of Mechanical Engineering, Universiti Malaysia Pahang, \\ 26600 Pekan, Pahang, Malaysia, \\ ${ }^{2}$ Automotive Engineering Centre, Universiti Malaysia Pahang, \\ 26600 Pekan, Pahang, Malaysia
}

\begin{abstract}
Friction stir welding (FSW) of aluminium and magnesium alloys face high demands in automotive and aerospace application due to its advanced and lightweight properties. FSW is an emerging solid state joining process in which the material that is being welded does not melt and recast. The main objectives of this project are to perform model updating based on finite element analysis (FEA) and experimental modal analysis (EMA) of dissimilar material of aluminium alloy AL 7075 and magnesium alloy AZ 31B. Modal properties such as natural frequencies, mode shapes are obtained and compared between FEA and EMA. The discrepancies of first five modes natural frequencies are below than $10 \%$ and the model updating have been conducted to minimize the error between two methods. This model updating are based on sensitivity analysis in order to make sure which parameters are given more influence in this structural dynamic analysis. Young's modulus and Poisson's ratio both materials are selected in the model updating process. After perform model updating, total average error of the natural frequencies of dissimilar friction stir welding plate is improved significantly.
\end{abstract}

\section{Introduction}

Many industrial fields give much attention which focusing on aluminium and magnesium alloys due to escalating appeal for further fuel-efficient vehicles to deduct the devouring of energy and more environmental friendly [1-2]. For their practical applications in market production, bonding and welding technologies should be given a colossal attention in addition to consider issues such as alloy design, microstructure control, plastic forming, casting, and surface treatment [3]. Both of these alloys are attractive to be applied in automotive structure for improving energy efficiency, which also leads to lessening the emission of greenhouse affecting gases. In order to ensure these alloys take place in automotive structures, dissimilar joint between magnesium and aluminum alloys is required [4]. Dissimilar metal joining also escalates in demand due to the good mechanical properties through the combination and also gives good corrosion resistance [5]. Joining method chosen is friction stir welding (FSW) which can be describes as a solid-state welding process, relatively novel joining technology, which has caught the interest of many industrial sectors, not only in automotive, but also aeronautic and transportation due to variation of advantages and vivid industrial potential. The process adds new possibilities within component design and allows more economical and environmentally efficient use of materials [6]. It was notified that using $\mathrm{Al}$ alloys and $\mathrm{Mg}$ alloys can provide distinct weight savings instead of using steel and cast iron [7].

For this paper, finite element analysis (FEA) method was picked for the purpose of theoretical approach by collective data of natural frequencies and mode shape in order to diagnose basic dynamic structure of plate. FEA involved the utilization of CAD Simulation software to illustrate the plate. Meanwhile for experimental modal analysis (EMA), impact hammer test is conducted to gain the modal properties. In this paper, modal properties are rectified using both methods, FEA and EMA which normal analysis mode in FEA order to select the most reliable model. From result obtained, model updating will be conducted to modify the correlation between experiment and numerical counterparts.

\section{Welding}

In industry, application of welding joining method experiences a high demand and become one of the most frequently method chosen for a mass production [8]. Welding is a fabrication process that is used to join materials together such as metals or thermoplastics in which the materials placed together exactly at the point to be bonded. FSW is being introduced approximately around last decade [9], is a solid state welding process

\footnotetext{
Corresponding author: mshahrir@ump.edu.my
} 
that normally used for welding soft materials like aluminium and magnesium alloys and in addition, to dissimilar metals that frequently facing a problem due to the hard in joining by conventional fusion techniques [10-11]. FSW reveals many advantages such as low distortion and wide chemical tolerance due to the heat input in the process is below the melting point [12]. Besides, the mechanical strength is high due to grain refinement in the heat affected zone (HAZ), low pollutions and low costs $[11,13]$.

In order to acquire an excellent result in joining of FSW and good weld quality, tool design if one of the vital criteria that needed to be consider [14-15]. Tool materials should have good thermal fatigue strength to resist repeated heating and cooling cycles, good fracture toughness to resist the damage during plunging and dwelling, good machinability to ease manufacture of complex features on the shoulder and probe, and have an affordable cost [16]. AISI H13 is a type of steel chosen for fabrication of welding tool in this study due to ease in machinability. Image and dimension of FSW tool can be seen in Figure 1 and Table 1 respectively below.

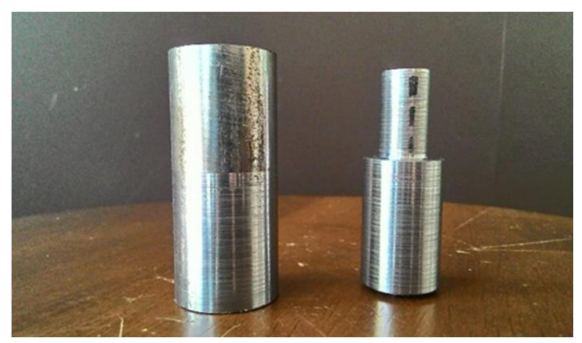

Fig. 1. FSW tool design

Table 1. FSW tool dimension

\begin{tabular}{|c|c|}
\hline Tool Parts & Dimensions \\
\hline Holder diameter, a $(\mathrm{mm})$ & 10.0 \\
\hline Holder length, b $(\mathrm{mm})$ & 19.0 \\
\hline Shoulder diameter, D $(\mathrm{mm})$ & 9.0 \\
\hline Shoulder length, c $(\mathrm{mm})$ & 5.0 \\
\hline Pin diameter, d $(\mathrm{mm})$ & 3.0 \\
\hline Pin length, $1(\mathrm{~mm})$ & 1.7 \\
\hline D/d ratio of tool & 3.0 \\
\hline
\end{tabular}

FSW experiment process was conducted by using vertical milling machine. Dissimilar FSW process is carried out by placing the high strength AL 7075 at the retreating side (RS) and by placing the AZ $31 \mathrm{~B}$ at the advancing side (AS) since if the weaker alloy is located at retreating side (RS), the fabricated weld will become weaker than the weaker alloy is at retreating side (RS) [17]. Figure 2 shows the setup of specimen for FSW. The process parameters which have the greater influence on the tensile strength of dissimilar FSW joints are identified as rotational speed (RS), transverse speed (TS) and tilt angle. It is important in order to produce a high quality joint for FSW process. Welding parameter set up for this study can be referring in Table 2 .

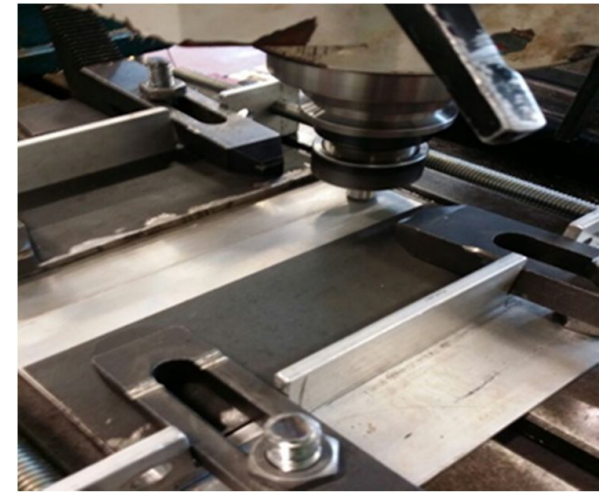

Fig. 2. FSW specimen set up

Table 2. Welding parameter for AL7075 and AZ31B

\begin{tabular}{|c|c|c|}
\hline $\begin{array}{c}\text { Rotational Speed } \\
(\mathbf{r p m})\end{array}$ & $\begin{array}{c}\text { Transverse Speed } \\
(\mathbf{m m} / \mathbf{m i n})\end{array}$ & Tilt Angle $\left.\mathbf{(}^{\circ}\right)$ \\
\hline 700 & 170 & 1 \\
\hline
\end{tabular}

\section{Finite Element Modeling and Analysis}

Finite element analysis (FEA) is a computational system generally used to predict the behavior of structures. It is mostly valuable to analyze those conditions which cannot be directly studied directly by experimentation, and thus, able to provides valuable information that cannot be obtained in more straight ways [18]. In FEA, normal mode analysis is performed on the finite element model of the dissimilar plate structure in order to obtain the dynamic properties of the structure, which are the natural frequencies, damping ratios and the mode shapes. Elements of dissimilar plates are model in MSC Nastran Patran as shown in Figure 3. Nominal properties of both structure are tabulated in Table 3.

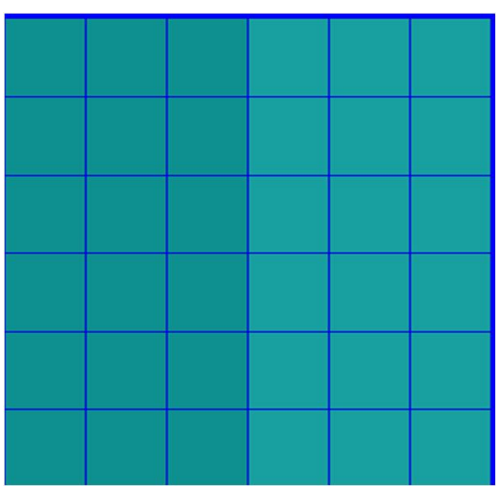

Fig. 3. Meshing element of dissimilar plates in FE

Table 3. Material properties of AL 7075 and AZ 31B

\begin{tabular}{|c|c|c|}
\hline Properties & AL 7075 & AZ 31B \\
\hline Density $\left(\mathrm{kg} / \mathrm{m}^{3}\right)$ & 2820 & 1770 \\
\hline Modulus of elasticity $(\mathrm{GPa})$ & 72 & 45 \\
\hline Poisson Ratio & 0.33 & 0.35 \\
\hline
\end{tabular}


From the numerical result, the values of natural frequencies and mode shapes of the dissimilar plates are obtained and tabulated in Table 4 below.

Table 4. Natural frequencies and mode shapes from FEA

\begin{tabular}{|c|c|c|}
\hline Mode & $\begin{array}{c}\text { Natural } \\
\text { Frequency (Hz) }\end{array}$ & Mode Shape \\
\hline 1 & 180.85 & \\
\hline 2 & 236.51 & \\
\hline 3 & 364.70 & \\
\hline 4 & 429.27 & \\
\hline 5 & & \\
\hline & & \\
\hline & & \\
\hline & & \\
\hline
\end{tabular}

\section{Experimental Modal Analysis}

Experimental modal analysis (EMA) or sometimes called as modal testing, is the process of extracting dynamic characteristics of a system, machinery or structure experimentally [19]. Confirmation for the accuracy of a result obtained in finite element analysis is usually validated by EMA [20-22]. The most regularly used technique of conducting the experiment is by using impact hammer as an actuator, an accelerometer as the sensor and a Fast Fourier Transform (FFT) analyzer to obtain the system Frequency Response Function (FRFs) [23].

Impact hammer test is a method of testing that allows user to acquire natural frequency, damping ratio and mode shapes of test structure. Indeed, this test is simple to implement but it is tough to obtain a consistent results. In this project, free-free boundary condition is set up for the flat plates by placing the specimen on sponge. Roving accelerometer method is chosen, and 36 node points are picked for knocking point. Figure 4 shows how the specimen is placed on the sponge and the accelerometer is placed on $1^{\text {st }}$ nodes on the specimen. The experiment is set up as shown in Figure 4.

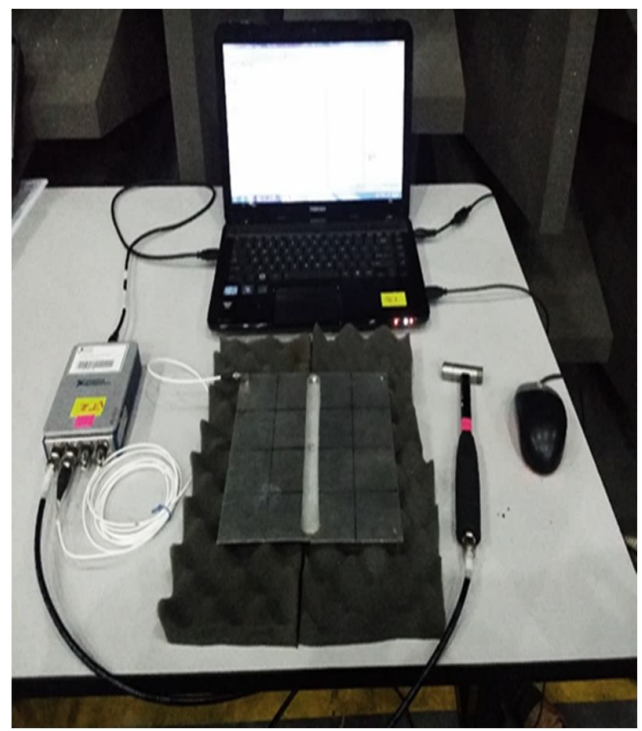

Fig. 4. Set up for EMA

From the experimental modal testing, results of natural frequencies and mode shapes are tabulated in Table 5 below.

Table 5. Natural frequencies and mode shapes from EMA

\begin{tabular}{|c|c|c|}
\hline Mode & $\begin{array}{c}\text { Natural } \\
\text { Frequency (Hz) }\end{array}$ & Mode Shape \\
\hline 1 & 178 & \\
\hline 2 & 228 & \\
\hline 3 & 318 & \\
\hline 4 & 384 & \\
\hline & & \\
\hline & & \\
\hline & & \\
\hline & & \\
\hline
\end{tabular}




\begin{tabular}{|l|l|l|}
\hline 5 & 426 &
\end{tabular}

\section{Correlations and Finite Element Model Updating}

Correlation of data that was gained through finite element analysis and modal testing are showed in order to analyze the discrepancies existed between those two sets of data. In addition, correlation of data is essential in order to have accurateness estimation on the existing plate model. Table 6 exhibits the correlation of natural frequencies of dissimilar plates structure that was gathered via experimental and numerical (finite element) analysis. Value of discrepancies between those two sets of data was calculated by accepting the value obtained through experiment as the actual value. As illustrated, the percentage of error that exists is significantly high in second and third modes.

Table 6. Correlation of natural frequencies between EMA and FEA.

\begin{tabular}{|c|c|c|c|}
\hline Mode & $\begin{array}{c}\text { Numerical } \\
\text { Natural } \\
\text { Frequency } \\
(\mathbf{H z})\end{array}$ & $\begin{array}{c}\text { Experimental } \\
\text { Natural } \\
\text { Frequency } \\
\mathbf{( H z )}\end{array}$ & $\begin{array}{c}\text { Percentage } \\
\text { of Error } \\
\mathbf{( \% )}\end{array}$ \\
\hline 1 & 186.85 & 178 & 4.87 \\
\hline 2 & 236.51 & 228 & 3.73 \\
\hline 3 & 364.70 & 318 & 14.69 \\
\hline 4 & 429.27 & 384 & 11.79 \\
\hline 5 & 478.90 & 426 & 12.42 \\
\hline & & $\begin{array}{c}\text { Total average } \\
\text { error }\end{array}$ & 9.52 \\
\hline
\end{tabular}

In order to reduce the existing discrepancies, model updating procedure was implemented on the finite element model of dissimilar plate structure, hence improves the model to have better correlation with the actual structure. There are dual approaches of model updating which are direct method and sensitivity method [19]. Model updating will be performed as an optimization technique and being presented by the structural optimization capability [24-27]. Several updating parameters which are Young's modulus and Poisson ratio for both materials were considered to be included in model updating procedure. The number of updating parameters was kept to be less than number of modes to be updated in order to avoid ill-conditioning problem in updating procedure. EMA result becomes as the benchmark for the comparison as the results are more reliable based on the FRF and coherence graph while taking results. The objective function for the prediction error in model updating optimization is defined as

$$
g(x)=\sum_{i=1}^{n} W\left(\frac{w_{i}^{e}}{w_{i}^{c}}-1\right)^{2}
$$

where $w_{i}^{e}$ and $w_{i}^{c}$ are the experimental and computational natural frequencies respectively, with $W$ as the real positive weighing factor. The prediction of the modal data is bestowed for detraction in the updating operation. Structural optimization is proven to be an effective algorithm for solving the sensitivity of parameters.

Table 7. Comparison of discrepancies between initial and updated results.

\begin{tabular}{|c|c|c|c|c|c|}
\hline \multirow{2}{*}{ Mode } & \multicolumn{5}{|c|}{ Natural Frequency (Hz) } \\
\cline { 2 - 6 } & EMA & $\begin{array}{c}\text { Initial } \\
\text { FEA }\end{array}$ & $\begin{array}{c}\text { Initial } \\
\text { (\%) of } \\
\text { Error }\end{array}$ & $\begin{array}{c}\text { Updated } \\
\text { FEA }\end{array}$ & $\begin{array}{c}\text { After } \\
\text { Updating } \\
\text { \% of } \\
\text { Error }\end{array}$ \\
\hline 1 & 178 & 186.85 & 4.97 & 178.46 & 0.26 \\
\hline 2 & 228 & 236.51 & 3.73 & 226.93 & 0.47 \\
\hline 3 & 318 & 364.70 & 14.69 & 357.93 & 12.56 \\
\hline 4 & 384 & 429.27 & 11.79 & 413.50 & 7.68 \\
\hline 5 & 426 & 478.90 & 12.42 & 460.14 & 8.01 \\
\hline & & $\begin{array}{c}\text { Total } \\
\text { average } \\
\text { error }\end{array}$ & 9.52 & $\begin{array}{c}\text { Total } \\
\text { average } \\
\text { error }\end{array}$ & 5.61 \\
\hline
\end{tabular}

Table 8. Changes of updating parameters from the initial values.

\begin{tabular}{|c|c|c|c|}
\hline Parameter & I & II & III \\
\cline { 2 - 4 } & $\begin{array}{c}\text { Initial } \\
\text { Value }\end{array}$ & $\begin{array}{c}\text { Updated } \\
\text { Value } \\
\text { (Upper) }\end{array}$ & $\begin{array}{c}\text { Updated } \\
\text { Value } \\
\text { (Lower) }\end{array}$ \\
\hline $\begin{array}{c}\text { Young's } \\
\text { Modulus of } \\
\text { AL7075 (GPa) }\end{array}$ & 72 & 64 & 80 \\
\hline $\begin{array}{c}\text { Young's } \\
\text { Modulus of } \\
\text { AZ31B (GPa) }\end{array}$ & 45 & 46 & 44 \\
\hline $\begin{array}{c}\text { Poisson Ratio } \\
\text { of AL7075 }\end{array}$ & 0.33 & 0.36 & 0.30 \\
\hline $\begin{array}{c}\text { Poisson Ratio } \\
\text { of AZ31B }\end{array}$ & 0.35 & 0.38 & 0.32 \\
\hline
\end{tabular}

\section{Conclusions}

This study was carried out to correlate the experimental modal data to the data gathered from finite element analysis of a dissimilar plate structure. A finite element model of the plate structure was produced and the percentage of errors between those two sets of data was obtained and the study was furthered into performing model updating procedure in order to reduce the existing percentage of errors. The updating procedure is considered as parameter identification and strikes to improve numerical prediction to be as closely as possible to the actual structure. 
Four parameters were chosen as the updating parameters and correlation was done based on the first five measured natural frequencies. The results of this investigation show that discrepancy is unavoidable when constructing model for a structure because of inaccuracies in parameters assumption and simplification in process of modeling. However, this inconsistency between the prediction model and the actual structure can be improved by carrying out model updating procedure.

It is recommended that further research be undertaken by including the joint element during modeling process. Therefore, procedure of model updating can be carried out at the joint element and joint properties can be chosen as one of the updating parameters. At the end, the updated finite element model structure can possibly exhibit more accurate and reliable numerical prediction model for future research.

\section{Acknowledgements}

This work was supported and funded by Universiti Malaysia Pahang (UMP) under RDU 150335.

\section{References}

[1] M. K. Kulekci, "Magnesium and its alloys applications in automotive industry," The International Journal of Advanced Manufacturing Technology, vol. 39, pp. 851865, 2008.

[2] W. S. Miller, L. Zhuang, J. Bottema, A. J. Wittebrood, P. De Smet, A. Haszler, et al., "Recent development in aluminium alloys for the automotive industry," Materials Science and Engineering: A, vol. 280, pp. 37-49, 3/15/ 2000.

[3] Y. J. Kwon, I. Shigematsu, and N. Saito, "Dissimilar friction stir welding between magnesium and aluminum alloys," Materials Letters, vol. 62, pp. 3827-3829, 8/31/ 2008.

[4] R. Borrisutthekul, Y. Miyashita, and Y. Mutoh, "Dissimilar material laser welding between magnesium alloy AZ31B and aluminum alloy A5052-O," Science and Technology of Advanced Materials, vol. 6, pp. 199-204, 3// 2005.

[5] E. Taban, J. E. Gould, and J. C. Lippold, "Dissimilar friction welding of 6061-T6 aluminum and AISI 1018 steel: Properties and microstructural characterization," Materials \& Design (1980-2015), vol. 31, pp. 2305-2311, 5// 2010 .

[6] D. Muruganandam and D. S. lal Das, "Friction Stir Welding Process Parameters for Joining Dissimilar Aluminum Alloys," International Journal of Mechanical Engineering \& Technology (IJMET), vol. 2, pp. 25-38, 2011.

[7] L. Liu, D. Ren, and F. Liu, "A review of dissimilar welding techniques for magnesium alloys to aluminum alloys," Materials, vol. 7, pp. $3735-3757,2014$.
[8] Y. Gori and R. P. Verma, "Experimental Fatigue Life Estimation of AA5083 Aluminium Alloys Welded by Two Welding Processes-Gas Metal Arc (GMA) Welding and Friction Stir Welding (FSW)," Journal of Graphic Era University, vol. 5, pp. 10-15, 2017.

[9] J. P. Bergmann, M. Grätzel, R. Schürer, A. Regensburg, and M. Weigl, "Advances and Potentials in Friction Stir Welding of Aluminum Alloys," in Key Engineering Materials, 2016, pp. 137-142.

[10] S. D. Meshram, A. G. Paradkar, G. M. Reddy, and S. Pandey, "Friction stir welding: An alternative to fusion welding for better stress corrosion cracking resistance of maraging steel," Journal of Manufacturing Processes, vol. 25, pp. 94-103, 1// 2017.

[11] A. F. Hasan, C. J. Bennett, P. H. Shipway, S. Cater, and J. Martin, "A numerical methodology for predicting tool wear in Friction Stir Welding," Journal of Materials Processing Technology, vol. 241, pp. 129-140, 3// 2017.

[12] R. Thakur and P. S. Bajwa, "Friction Stir Welding of $5 \mathrm{xxx}$ series Aluminium Alloys A Literature Survey," 2016.

[13] Z. Zhang, Q. Wu, and H. Zhang, "Prediction of fatigue life of welding tool in friction stir welding of AA6061-T6," The International Journal of Advanced Manufacturing Technology, vol. 86, pp. 3407-3415, 2016.

[14] A. Fall, M. H. Fesharaki, A. R. Khodabandeh, and M. Jahazi, "Tool wear characteristics and effect on microstructure in Ti-6Al-4V friction stir welded joints," Metals, vol. 6, p. 275, 2016.

[15] K. Kumar and S. V. Kailas, "The role of friction stir welding tool on material flow and weld formation," Materials Science and Engineering: $A$, vol. 485, pp. 367-374, 6/25/ 2008.

[16] Y. Zhang, X. Cao, S. Larose, and P. Wanjara, "Review of tools for friction stir welding and processing," Canadian Metallurgical Quarterly, vol. 51, pp. 250-261, 2012.

[17] S. R. Kumar, V. S. Rao, and R. Pranesh, "Effect of welding parameters on macro and microstructure of friction stir welded dissimilar butt joints between AA7075-T651 and AA6061-T651 alloys," Procedia Materials Science, vol. 5, pp. 1726-1735, 2014.

[18] D. Burr, "The use of finite element analysis to estimate the changing strength of bone following treatment for osteoporosis," ed: Springer, 2016.

[19] S. N. Zahari, A. A. R. Zakaria, and M. S. M. Sani, "A review on model updating of joint structure for dynamic analysis purpose," 2015.

[20] N. A. Z. Abdullah, M. S. M. Sani, M. M. Rahman, and I. Zaman, "Correlation of Numerical and Experimental Analysis for Dynamic Behavior of a Body-In-White (BIW) Structure," 2016. 
[21] M.H.N. Izham, N.A.Z. Abdullah, S. N. Zahari, and M.S.M. Sani, "Structural dynamic investigation of frame structure with bolted joints," in Journal MATEC Web of Conference, 2017, pp. 1-9.

[22] M.S.M. Sani, N.A. Nazri, S.N. Zahari, N.A.Z Abdullah, and G. Priyandoko, "Dynamic Study of Bicycle Frame Structure," in IOP Conf. Series: Materials Science and Engineering 160 (2016) $012009 \quad$ doi:10.1088/1757899X/160/1/012009, 2016, pp. 1-8.

[23] N. A. Z. Abdullah, M. S. M. Sani, and N. A. Husain, "Model Updating of Go-Kart Structure in Structural Dynamics," 2015.

[24] S. N. Zahari, M. S. M. Sani, N. A. Husain, M. Ishak, and I. Zaman, "Dynamic analysis of friction stir welding joints in dissimilar material plate structure," Jurnal Teknologi, vol. 78(6-9), pp. 57-65, 2016.

[25] N.A.Z. Abdullah, M.S.M. Sani, M.M. Rahman, and I. Zaman, "A review on model updating in structural dynamics," in IOP Conference Series: Material Science and Engineering, 2015, pp. 16.

[26] M.N. Abdul Rani, D. Stancioiu, M.A. Yunus, H. Ouyang, H. Deng and S. James, "Model updating for a welded structure made from thin steel sheets," Appl. Mech. Material, Vol 70, Aug 2011, pp. 117-122.

[27] M.N. Abdul Rani, S. Kasolang and M.H. Othman, "Finite element modelling and modal based updating for the dynamic behaviour of a laser spot welded structure," 23rd International Congress on Sound and Vibration (ICSV2016). 